\title{
RECENT DEVELOPMENTS ON THE USE OF DRAINAGE GEOCOMPOSITES IN CAPPING SYSTEMS
}

\section{Daniele Cazzuffi ${ }^{*, 1}$ and Piergiorgio Recalcati ${ }^{2}$}

${ }^{1}$ CESI Spa, via Rubattino 54, 20134 Milano, Italy

2 Tenax Spa, via Industria 3, 23897 Viganò, Italy

Article Info:

Received:

22 Februray 2018

Revised:

31 August 2018

Accepted:

17 September 2018

Available online:

30 September 2018

Keywords:

Capping systems

Drainage geocomposites

Harmonized standards

Transmissivity tests

Compressive creep tests

\section{ABSTRACT}

This paper reviews the different requirements imposed from the European harmonised standards for the use of different types of drainage geocomposites in the capping systems of landfills. The results of specific experimental investigations on the behaviour of drainage geocomposites in such applications are presented.

\section{INTRODUCTION}

The need to follow the regulations foreseen by the European Union - Council Directive 1999/31/EC (hereforth referred to as EUCD) related to the design and maintenance of landfill, and most of all by the local national codes that have been adopted country by country starting from the Directive itself, can sometimes represent a technical and economical challenge for designers and for landfill owners.

The EUCD defines a landfill as a site for the deposit of the waste onto or into land (i.e. underground), including internal waste disposal sites (i.e. landfill where a producer of waste is carrying out its own waste disposal at the place of production), and a permanent site (i.e. more than one year) which is used for temporary storage of waste. In particular, the Landfill Directive defines three different categories of wastes: hazardous waste, non-hazardous waste and inert waste.

As already known, the function of the capping system is to: insulate waste from the external environment; control rain water from entering into the landfill body; prevent surface water from entering into the landfilled wasteand avoid the risk of subsidence and sliding.

According to the EUCD, the materials to collect and drain biogas, the creation of the barrier system and the removal of rainfall water, should consist of thick layers of natural materials, respectively gravel and compacted clay.
In practise, this is sometimes very difficult to achieve, as natural materials may not be available close to the site.

Depending upon the type of waste, different systems are proposed to allow gas drainage (required for non-hazardous wastes only), an artificial sealing liner (required for hazardous wastes only), an impermeable mineral layer (required for every type of waste), a drainage layer $>0.50 \mathrm{~m}$ and a top soil cover $>1.00 \mathrm{~m}$, both required for every type of waste.

It's important to note the following: although the Directive prescribes a gas drainage layer for non-hazardous waste in general, in reality it is necessary for all landfills receiving biodegradable waste.

Wherever the national regulations allow it, the materials listed above are widely substituted, with geosynthetics (see for example the case history described by Cazzuffi et al., 2009).

The scenarios foreseen by the Italian code derived from the European directive and the corresponding sections using geosynthetics are shown in Figure 1.

There are several reasons to substitute natural material with geosynthetics. The most relevant are technical reasons: the stratigraphy foreseen by the European directive and by the Italian regulation are sometimes not compatible with the geometry of the landfill bodies. There are some cases where the landfill geometry has been designed and finalised well before the Directive was active, and therefore the surfaces are too steep and long to guarantee the sta- 


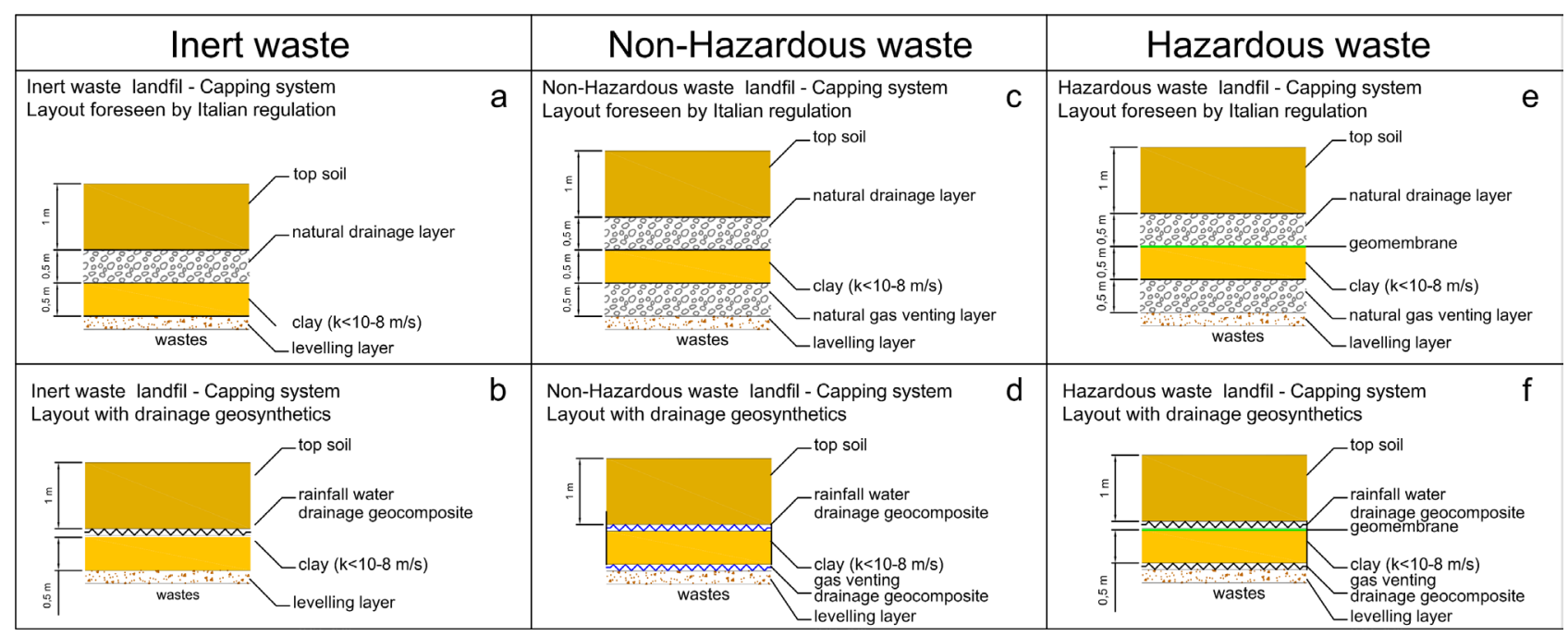

FIGURE 1: Capping system: layout foreseen from Italian code for inert waste landfill (a), non-hazardous waste landfill (c) and hazardous waste landfill (e); possible alternatives with geosynthetics for inert waste landfills (b), non-hazardous waste landfills (d) and hazardous waste landfills (f).

bility of the natural layers. This type of problem is amplified whenever the site is in a seismic areawhen the Eurocodes 7 and 8 have to be followed.

Another reason is economical: granular materials used to guarantee the proper drainage have to be clean coarse sands or gravel. The need toimport large quantities of an expensive material may present difficulties to collect all the required material from the same quarry or source. This could lead to difficulties to guarantee a proper quality control on site, making this solution extremely expensive (Riot and Cazzuffi, 2013).

For the drainage systems, in particular, the continuous evolution of the manufacturing process, together with a wider range of laboratory tests, allows us to obtain increasingly higher performance with evident advantages; not only in economic terms but also from the environmental point of view as less natural materials from quarries and subsequent excavation works are required.

The general rules of the Directive have been adopted in different ways in European countries, using more or less restrictive approaches. In Italy for example, the drainage layers for gas and water have to be granular layers having a minimum thickness of $0.50 \mathrm{~m}$, and as for the water drainage layer, it is recommended that no water head should develop within the granular layer, but no indication is given in terms of hydraulic conductivity. The same lack of information about the hydraulic conductivity is also present for the gas venting layer (Recalcati and Salis, 2012). Another point that can be made is the lack of any clear reference to the possibility to adopt geosynthetics; a method widely used even well before the Directive was written. Because of this situation there are local authorities that are not allowing the use of alternative solutions to the natural layers.

The paper describes in detail some examples of technical developments related to testing and installation of drainage geocomposites in the drainage systems for landfills capping.

\section{HARMONIZED STANDARDS FOR DRAINAGE GEOCOMPOSITES}

European standards on geotextiles and geotextile-related products are developed by CEN/TC 189 Geosynthetics. International standards are developed by ISO/TC 221 Geosynthetics.

Over the past 20 years both committees have issued more than 100 standards and amendments to standards. In particular, CEN TC 189 is the Technical Committee taking care of harmonized European product standards (hENs) related to geosynthetics.

The scope of this group is the standardization related to geosynthetics; terminology, sampling before testing, identification and marking rules, test methodsand requirements related to their intended use.

The TC is currently divided into 6 Working Groups (WG) each relating to specific items related to geosynthetics definition and properties:

- CEN/TC 189/WG 1 - Geotextiles and geotextile-related products - General and specific requirements of harmonized technical specifications;

- CEN/TC 189/WG 2 - Terminology, identification, sampling and classification;

- CEN/TC 189/WG 3 - Mechanical testing;

- CEN/TC 189/WG 4 - Hydraulic testing;

- CEN/TC 189/WG 5 - Durability;

- CEN/TC 189/WG 6 - Geosynthetic barriers - General and specific requirements.

In particular, WG1 is the working group taking care of the development of Harmonized Standards for geotextiles and geotextile-related products to a specific field of application.

During recent years, two specific European harmonized standards have been developed for application of geosynthetics in waste disposals (EN 13257: 2016-Geotextiles and geotextile-related documents - Characteristics required 
foruse in solid waste disposals and EN 13265: 2016 - Geotextiles and geotextile-related products - Characteristics required for use in liquid waste containment projects).

Moreover, in the specific case of drainage systems, the harmonized standard EN 13252: 2016 (Geotextiles and geotextile-related products - Characteristics required for use in drainage systems) should be used.

\subsection{EN 13252: 2016 - Geotextiles and geotextile-re- lated products - Characteristics required for use in drainage systems}

This standard specifies characteristic properties, test method limits and their significance level for drainage systems.

The main functions of geotextiles and geotextile-related products used in drainage systems are filtration, separation and drainage. The specification defines which functions and conditions of use are relevant (see Table 1 for drainage function).

The manufacturer of the product shall provide the necessary data based on the requirements and test methods described in this European Standard.

In particular, the characteristics of a product are divided in:

- A: essential characteristic relevant to all conditions of use;

- S: relevant to specific conditions of use.

\section{DRAINAGE GEOCOMPOSITES IN CAPPING SYSTEMS}

\subsection{Design aspects}

Geosynthetic products that can effectively substitute granular drainage layers are the so-called drainage geocomposites. They are characterised by a draining medium, capable to allow a planar flow within its surface (drain core), and one or two filter layers (geotextiles) bonded to the surfaces of the geonet, whose function is to protect the passage of the fluid prevent the solid particles from entering the drainage medium and clog it.

The use of geosynthetics first of all gives to the owner and to the designer proven and certified information about the water flow capacity of the product. To have the same type of information with granular materials it would be necessary to run a larger number of tests and there can be uncertainties due to the possible variation of the properties of the gravel used.

Furthermore, the capping system has a reduced weight, a lower thickness (thus allowing an increase of the landfill volume) and the overall stability of the capping system can be improved.

The design of a drainage system using geosynthetics is based on the evaluation of the effective discharge capacity of the geocomposite and of the required water flow capacity under the design conditions. The drainage capacity of geosynthetics is evaluated though specific laboratory tests, while the required design flow rate has to be evaluated on the base on hydrologic studies.

As previously stated, the granular layer used (either nat- ural or synthetic) should guarantee that no hydraulic head is developed on top of it in case of rainfalllt is then necessary to choose a product capable to guarantee the discharge of the whole water amount that it is reasonable to assume will reach the drainage layer after migrating from the top soil layer.

If the drainage capacity is not adequate, the excess of water can cause the development of an uplift due to the water itself, and as a consequence a dramatic reduction in the functional properties at the interface between the topsoil and the drainage layer. Then, the stability of the topsoil can be compromised.

Precipitation intensity should be determined with a return time that is considered relevant and sufficient from the designer, and it should be carefully chosen. It is the task of the designer to evaluate if a persistent, long-lasting but not heavy rainfall is more dangerous than a heavy storm. In the second case the amount of water most probably will never reach the drainage layer but will runoff over the surface.

The critical rainfall intensity has to be evaluated to also consider the geometry of the surface and of the nature of the soil, or better of its hydraulic conductivity.

Once the critical rainfall intensity has been evaluated, it is then necessary to give an estimation of the percentage of water that will reach the drainage layer, taking into account the water that will be lost due to evapotraspiration, runoff and absorption in the soil.

The hydraulic flow rate within a granular layer can be determined in a complex way on the base of the geometry of the piezometric surface (Figure 2). However, if the length of the granular layer is much larger than its thickness, the real shape of the piezometric surface is almost linear.

A simplified (yet conservative) approach, based on the assumption that the hydraulic flow within the granular layer is linear and uniform, is suggestible and strongly recommendable.

The maximum flow rate that can be transmitted by a drainage layer characterised by a hydraulic conductivity ' $k$ ' under a gradient " can be calculated using the flow equation proposed by Darcy:

$Q=k \cdot A \cdot i$

The flow rate corresponding to 1 meter width of draining layer is whose thickness is

$t Q=k \cdot t \cdot 1,00 \cdot i$

The transmissivity is equal to the specific flow rate divided by the gradient

$\Theta=k \cdot t \cdot 1,00$

The flow rate of a drainage geocomposite is measured according to EN ISO 12958. The flow rate per unit width is determined by measuring the quantity of water that passes through a test specimen in a specific time interval under different normal stress and different hydraulic gradient (typically $\mathrm{i}=1.0, \mathrm{i}=0.50$ and $\mathrm{i}=0.10$ ).

The hydraulic gradient is defined as the ratio between the difference in the piezometric water head between the 


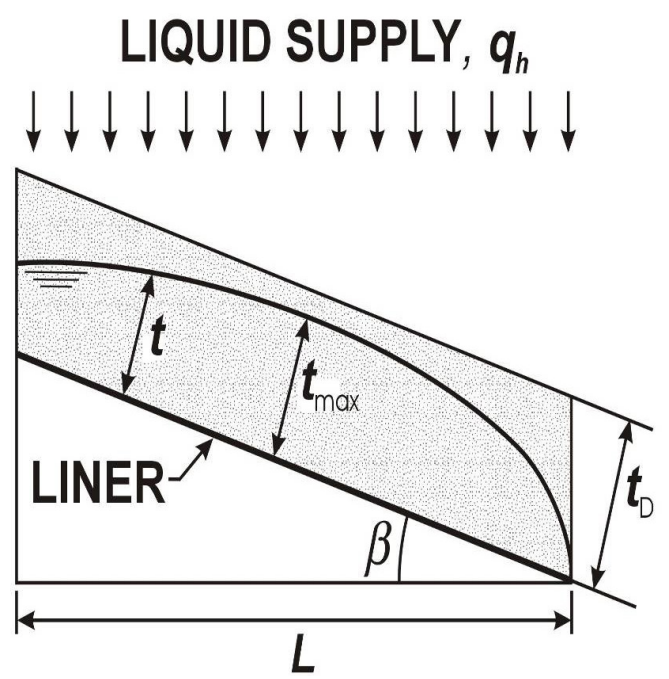

FIGURE 2: Piezometric surface within the granular medium of a capping system (Giroud e al., 2000).

upstream and downstream edges of the slope and the length of the slope itself; in the hypothesis of a steady flow, it is equal the ratio between the difference in level $(\mathrm{DH})$ and the length of drainage $(\mathrm{L})$, that corresponds the sinus of the slope angle.

$i=\sin \beta$

The results of the tests are represented in diagrams, having the normal pressure on the $\mathrm{x}$ axis and the flow rate measured in the lab on the $y$ axis; usually the $y$ axis is represented in logarithmic scale.

If the design gradient "' is represented on the flow rate diagram, then it is enough to choose the geocomposite that under the same gradient and the same normal pressure can guarantee a flow rate equal or greater to the design one Q.

If the design gradient "' is different from the values of the flow rate diagrams, it is possible to calculate the equivalent flow at the specific gradient by knowing the actual values at a different gradient using empirical formulas (Cancelli and Rimoldi, 1989).

Replacement of a natural granular layer with a geosynthetic can be justified only if it is possible to prove that the latter can guarantee at least the same performance not only in the short term, but most of all in the long term. It is important to remember that EN ISO 12958 gives information about the short-term behaviour of the geocomposite, being an index text, but by itself it is not sufficient to asses any long-term performance.

To take into account the real long-term performance of a draining geosynthetic under a constant normal load, it is necessary to apply factors of safety to the required flow rate in order to define an allowable flow rate.

In case of long steep slopes, the state of stress to which the drainage layer will be subjected has also a tangential component that needs to be taken into account (Muller et al, 1998; Yeo and Hsuan, 2007).

A fundamental parameter, sometimes neglected in design, is the long-term compressive creep resistance of the geocomposite (see also Cazzuffi and Recalcati, 2016). The geosynthetic shall be capable to resist to high pressure for short duration (operation machineries passing over the material during installation) and lower but long-lasting pressures during the whole design life (both normal or inclined).

\subsection{Experimental investigations on the behaviour of drainage geocomposites in capping systems}

Geocomposites have been successfully designed as surface water removal layer in landfill final covers or as gas venting layer for decades. The most critical engineering property of a geocomposite is its in-plane flow capacity under design loads and site-specific boundary conditions. The design parameter used to quantify the in-plane flow capacity is either the flow rate per unit width of the geosynthetic or hydraulic transmissivity (flow rate per unit width of geosynthetic and per unit of hydraulic gradient "i"). Transmissivity is applicable to laminar flow conditions (EN ISO 12958) and it is defined as:

$\Theta=k_{p} \cdot t=\frac{q}{i}$

where:

$\Theta=$ Hydraulic transmissivity $\left(\mathrm{m}^{3} / \mathrm{s} / \mathrm{m}\right)$

$\mathrm{q}=$ Flow rate per unit width $\left(\mathrm{m}^{3} / \mathrm{s} / \mathrm{m}\right)$

$\mathrm{k}_{\mathrm{p}}=$ In-plane hydraulic conductivity (permeability) $(\mathrm{m} / \mathrm{s})$

$\mathrm{i}=$ Hydraulic gradient $(-)$

$\mathrm{t}=$ Geocomposite thickness $(\mathrm{m})$

EN ISO 12958 covers the procedure for determining the flow rate per unit width within the manufactured plane of geosynthetics under varying normal compressive stresses and a constant head. This test method is limited to geosynthetics that allow continuous in-plane flow paths to occur parallel to the intended direction of flow.

The flow rate per unit width is determined by measuring the quantity of water that passes through a test specimen in a specific time interval under a specific normal stress and a specific hydraulic gradient. The hydraulic properties are measured with a testing equipment derived from that originally used by Darcy to study the water permeability of soil (Figure 3).

In order to measure the drainage capacity of the geonets and of the geocomposites the test apparatus is capable of applying differing values for the hydraulic gradient "i", as well as for the applied normal pressure, so as to simulate different possible operating conditions (varying overburden pressures).

According to EN ISO 12958, the geocomposite specimen may be tested in accordance to specific project boundary conditions that consist of:

- Geocomposite between two stiff HDPE liner (abbr. $\mathrm{H} / \mathrm{H})$;

- Geocomposite between one stiff and one layer of soil (abbr. S/H);

- Geocomposite between two soil boundaries (abbr. S/S).

Whichever is the type of test performed, the result obtained is an index value, representing the behaviour in the short term; however, a designer needs to have a value 

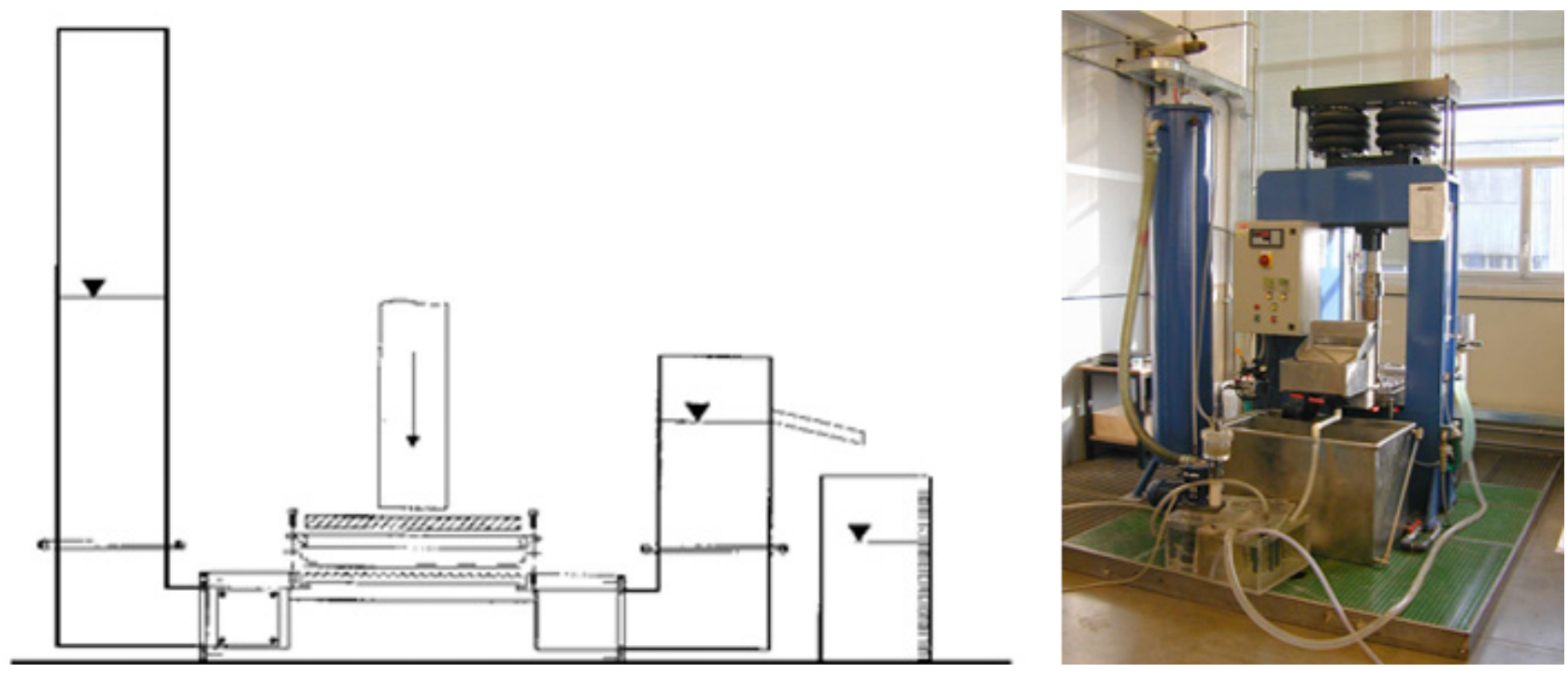

FIGURE 3: A constant head (in-plane) flow rate testing device for the evaluation of the drainage capacity of drainage geocomposites under normal pressure and for different hydraulic gradients.

that is representative of the performance of the product for the whole design life, or in other words a long-term allowable flow rate.

GRI Standard GC8 (2001) "Determination of the Allowable Flow Rate of a Drainage Geocomposite" presents a possible methodology for determining the allowable flow rate of a drainage geocomposite; from which the resulting value can be used directly in a hydraulic-related design. The method is based upon the concept of identifying the reduction factor for creep, chemical and biological clogging that may affect the long-term performance of the geocomposite.

The definitions and symbols specified in the GRI Standard GC8 apply. The fundamental equation for the evaluation of the Allowable Flow rate $\mathrm{Q}_{\text {allow }}$ is:

$Q_{\text {allow }}=q_{100} \cdot\left[\frac{1}{R F_{C R} \cdot R F_{C C} \cdot R F_{B C}}\right]$

where:

$\mathrm{Q}_{\text {allow }}=$ allowable Flow rate

$\mathrm{q}_{100}=$ initial flow rate determined under simulated condition for 100 hours duration

$\mathrm{RF}_{\mathrm{CR}}=$ Reduction Factor for creep to account for long-term behaviour

$\mathrm{RF}_{\mathrm{CC}}=$ Reduction Factor for chemical clogging

$\mathrm{RF}_{\mathrm{BC}}=$ Reduction Factor for biological clogging

It is very well known that, in the design by function approach, a drainage geocomposite must meet the following equation:

$F S=\frac{Q_{\text {allow }}}{Q_{\text {reqd }}}$

where:

$\mathrm{Q}_{\text {reqd }}$ is a required (or design) flow rate; the required flow rate can be determined from a water balance model such as the HELP model or other well-documented methods;

FS is the overall safety factor; generally, for landfill drainage, it is recommended a value of Safety Factor between
2 to 3 be used.

As seen before, the first aspect is measuring the flow rate under at different gradients but under a specific load condition (contacts and surcharge) with a test lasting at least 100 hours (Figure 4). The extended duration of the tests allows us to evaluate the long-term compressibility of the product; this is particularly important for geocomposites showing a brittle behaviour after a period longer than the normal duration of the transmissivity test.

To determine the Creep Reduction Factor, according to the standard EN ISO 25619-1:2008 “Geosynthetics -- Determination of compression behaviour -- Part 1: Compressive creep properties" the drainage core is placed under compressive stress and its reduction in thickness (deformation) is monitored over time.

Creep reduction factor RFcr is determined from 10,000 hours compressive creep data. In the absence of 10,000 hours creep data, designers must assess the applicability of the geocomposite with respect to structural stability under sustained loads.

The reduction factor for creep of the core is interpreted according to the following formulas, after Giroud et al. (2000) and they are summarized in the equation below:

$R F_{C R}=\left[\frac{\left(t_{C O} / t_{\text {original }}\right)-\left(1-n_{\text {original }}\right)}{\left(t_{C R} / t_{\text {original }}\right)-\left(1-n_{\text {original }}\right)}\right]^{3}$

where:

$\mathrm{RF}_{\mathrm{CR}}=$ reduction factor for creep

$\mathrm{t}_{\text {original }}=$ original thickness $(\mathrm{m})$

$\mathrm{t}_{\mathrm{co}}=$ thickness at 100 hours $(\mathrm{m})$

$t_{\mathrm{CR}}=$ thickness at >>100 hours, e.g., at 10.000 hours (m)

$\mathrm{n}_{\text {original }}=$ original porosity

$n_{\text {original }}=1-\frac{\mu}{\rho \cdot t_{\text {original }}}$

where:

$\mathrm{m}=$ mass per unit area $\left(\mathrm{kg} / \mathrm{m}^{2}\right)$

$r=$ density of the formulation $\left(\mathrm{kg} / \mathrm{m}^{3}\right)$ 
A creep curve where percentage thickness retained is plotted against a specific normal stress over time; if there is a linear-Log relationship between percentage thickness retained and time, this linear-Log relationship can be extrapolated to design life of a project to obtain thickness and reduction factor at, e.g., 30, 50 or 100 years (Figure 5).

There are specific conditions that can occur either during the installation of a product or during the lifetime of the product that cannot be simulated with the conventional creep test, but can be derived by a simple modification of it and can give important information to the designer or the job director in the choice of a product or at least in the procedure to be followed during installation.

In normal conditions, the surcharge applied to a drain- age geocomposite for a landfill capping does not exceed 20-50 kPa. However, it is possible that, for many reasons, during installation a higher state of stress is applied for a short time to the product.

This can happen for example during the installation of the geocomposite if any site equipment remains on top of the geocomposite or on top of a thin layer of soil. The equipment can apply a surcharge at least equal to 100-200 $\mathrm{kPa}$; after the removal of this surcharge the geocomposite should come back to a thickness as close as possible to the one it would have without the increased surcharge.

Different products can bring quite surprising results; in the following chart the results of a test performed on a PA monofilament geocomposite having an initial thickness of
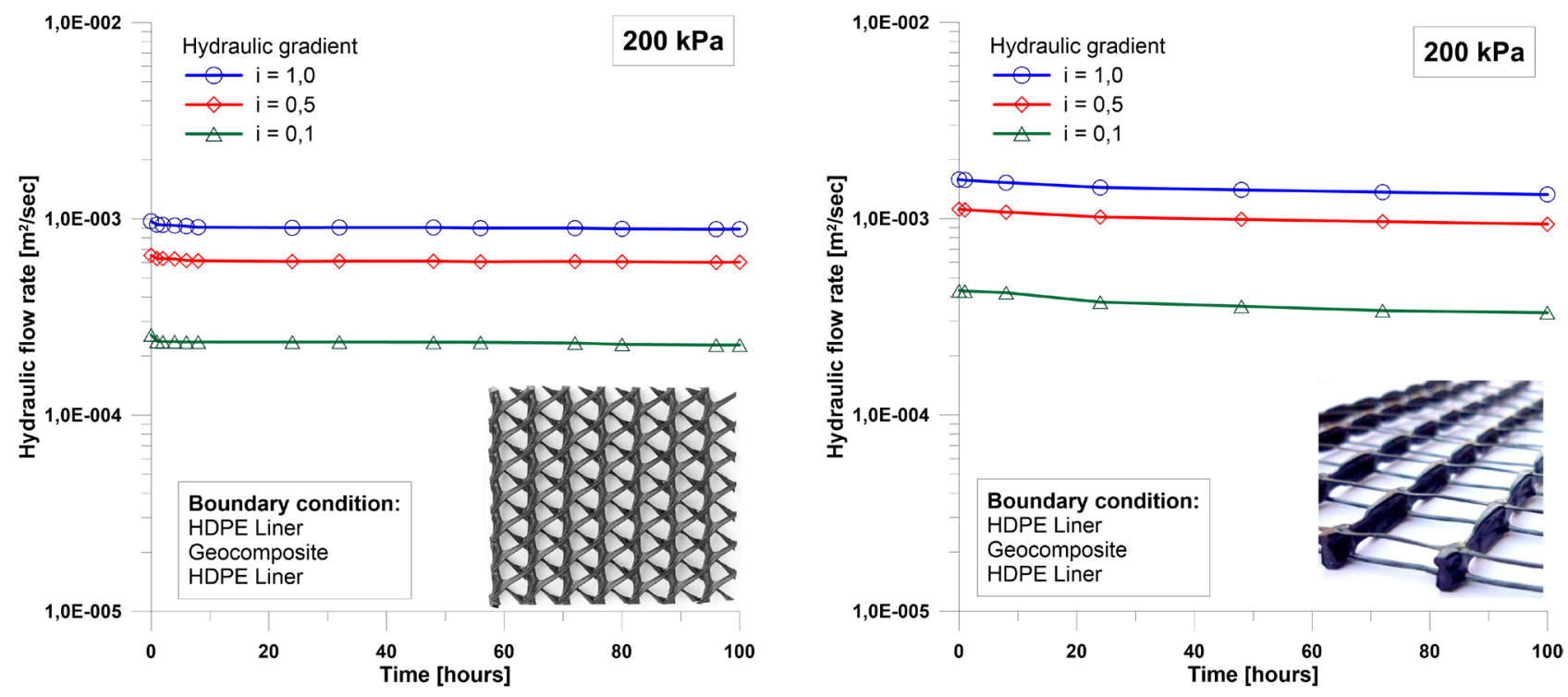

FIGURE 4: Long-term hydraulic flow rate on different geocomposites at $200 \mathrm{kPa}$.
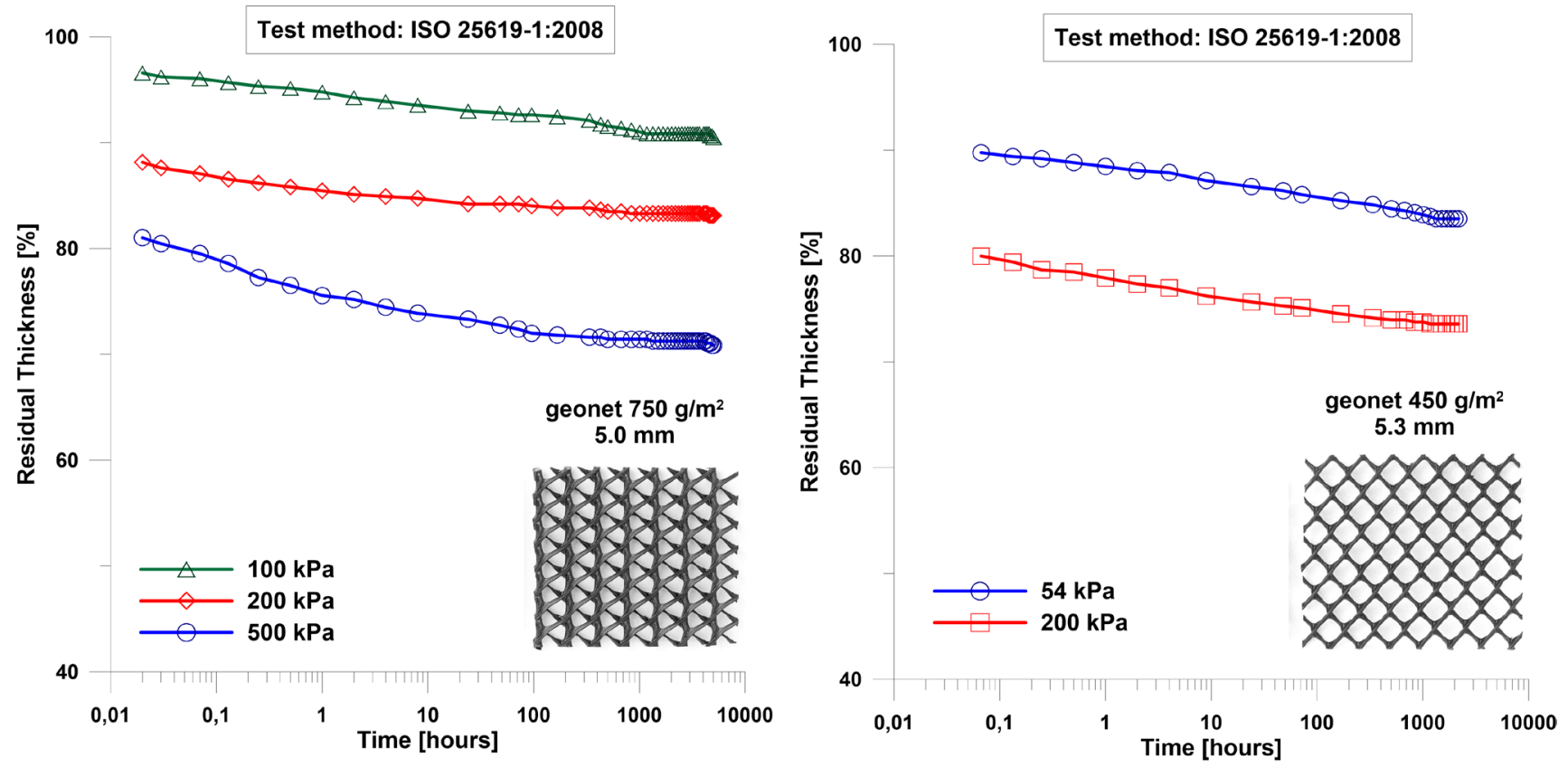

FIGURE 5: Creep curves obtained from compressive creep tests on different types of geonet. 
about $20 \mathrm{~mm}$ is shown. Five different samples were tested; four were subjet to a surcharge of $50 \mathrm{kPa}$ for over 100 hours; in one case a surcharge of $200 \mathrm{kPa}$ was applied for 1 hour and then removed rapidly reaching a constant surcharge of $50 \mathrm{kPa}$ (Figure 6).

By comparing the results, the presence of a residual plastic deformation in the last case that is not recovered even after 1000 hours is evident.

\section{CONCLUSIONS}

The use of drainage geocomposites in landfill capping systems represents a solution technically valid and sustainable; this is confirmed by thousands of examples all over the world.

European and International standards on geosynthetics are considered to be in continual progress. It is of fundamental importance that national technical regulations are continuously updated in order to take into account the progressive evolution typical of the development in manufacturing technologies of those materials and also in the related preparation of European and International standards on geosynthetics.

The influence of the the long-term water flow capacity as well as the compressive behavior under normal or inclined state of stress has been shown: these aspects should be evaluated in future revisions of the harmonized standards on drainage geocomposites.

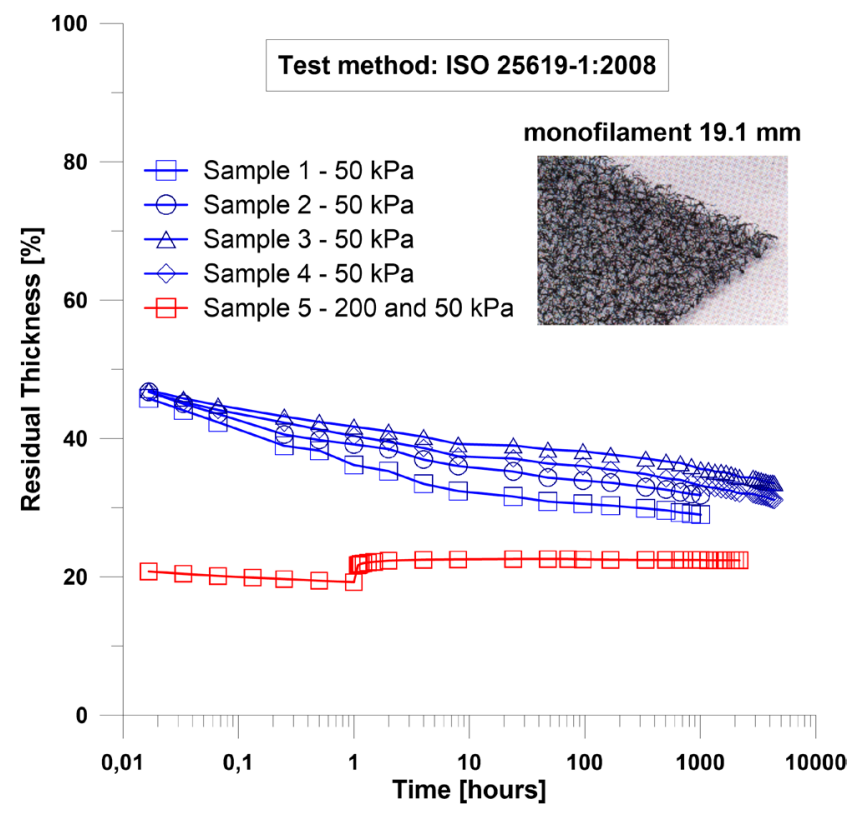

FIGURE 6: Creep curves obtained from compressive creep tests on monofilament geocomposite for different test procedures.
In order to avoid a wrong choice of drainage geocomposites because of an excessively restrictive interpretation of the rules and of the European Directive, it is necessary to test specific conditions that can occur during the installation of a product or during the lifetime of the product. This is important particularly when the real situation cannot be simulated with conventional creep tests, but it can be derived by a simple modification of it. This can give important information to the designer or the project manager for a correct choice of a product or at least in the procedure to be followed during installation.

\section{REFERENCES}

Cancelli, A., Rimoldi, .P. (1989). Design criteria for geosynthetic drainage system in waste disposal, Proceedings Sardinia '89. 2nd International Landfill Symposium, Porto Conte, Italy.

Cazzuffi D., Recalcati P. (2016) Experimental tests for a proper technical advancement and a correct design of drainage systems for landfills capping, Proceedings of GeoAmericas 2016, 3rd Pan-American Conference on Geosynthetics, Miami Beach, USA.

Cazzuffi, D., Recalcati, P., Tresso, G. (2009). Barrier and drainage geosynthetics systems for the capping of a polluted site in Milano industrial area, Proceedings of the International Symposium on Geotechnical Engineering, Ground Improvement and Geosynthetics, Bangkok, Thailand.

EN 13252 (2016). Geotextiles and geotextile-related products - Characteristics required for use in drainage systems, CEN, Brussels, Belgium.

EN 13257 (2016). Geotextiles and geotextile-related documents Characteristics required for use in solid waste disposals, CEN, Brussels, Belgium.

EN 13265 (2016) Geotextiles and geotextile-related products - Characteristics required for use in liquid waste containment projects, CEN, Brussels, Belgium.

EN ISO 12958 (2010). Geotextiles and geotextile-related products -- Determination of water flow capacity in their plane, CEN, Brussels, Belgium.

EN ISO 25619-1 (2008). Geosynthetics -- Determination of compression behaviour -- Part 1: Compressive creep properties, CEN, Brussels, Belgium..

European Union - Council Directive 1999/31/EC (1999). Landfill of waste, 26 April 1999.

Giroud, J.P., Zhao, A., Richardson, G. N. (2000). Effect of Thickness Reduction on Geosynthetic Hydraulic Transmissivity, Geosynthetics International, Vol. 7.

GRI - GC8 Standard (2001). Standard Guide for Determination of the Allowable Flow Rate of a Drainage Geocomposite, Geosynthetic Research Institute, USA.

Müller, W.W., Jakob, I., Tatzky-Gerth, R. (2008). Long-term water flow capacity of geosynthetic drains and structural stability of their drain cores, Geosynthetics International. 15(6): p. 437-451.

Recalcati, P., Salis, S. (2012). Capping systems and remediation technologies for waste landfills: technical and design evolution (in Italian), Proceedings of the XXV Italian Conference on Geosynthetics, Bologna, Italy.

Riot, M., Cazzuffi, D. (2013). Behaviour of draining geosynthetics for landfill capping systems, Proceedings of Sardinia '13 the Fourteenth International Waste Management and Landfill Symposium, Santa Margherita di Pula, Cagliari, Italy.

Yeo, S.-S., Hsuan, Y. G. (2013). The short and long-term compressive behaviour of high density polyethylene geonet and geocomposite at inclined conditions, Department of Civil, Architectural and Environmental Engineering, Drexel University, Philadelphia. 